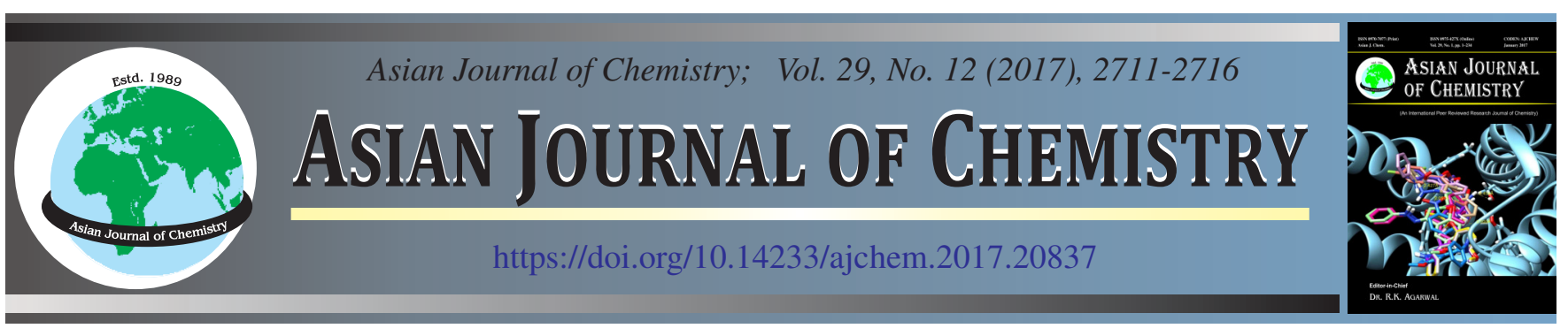

\title{
Influence of Temperature and Capping Molecules on the Synthesis of Cubic Structured Lead Sulfide Nanoparticles from Substituted Benzimidazole Dithiocarbamate Complex
}

\author{
C.S. Thangwane, T. XaBA ${ }^{*}$ and M.J. Moloto
}

Department of Chemistry, Vaal University of Technology, Private Bag X 021, Vanderbijlpark 1900, South Africa

*Corresponding author: Fax: +27 86 6906606, Tel:+27 16 9509820; E-mail: thokozanix@ vut.ac.za

\section{INTRODUCTION}

The synthesis of metal sulfide nanomaterials has been the topic of interest in the past decades due to their technological applications [1,2]. Semiconductors with reduced dimension display unique electronic, optical, magnetic and photochemical properties which are significantly differ from their bulk materials [3]. This is due to their high surface area to volume ratios and quantum confinement [4]. The introduction of capping agents during the synthesis of nanomaterials has proven to be significant lately due to their capability to prevent the overgrowth, aggregation as well as to control the structural characteristics of nanomaterials in a specific manner [5]. Capping agents such as amines [6] and thiols [7] are very good capping molecules that can be used to produce semiconductor nanoparticles below Bohr radius.

Among the group IV-VI metal chalcogenide, $\mathrm{PbS}$ is regarded as an important semiconductor material. It has a direct narrow band gap of $0.41 \mathrm{eV}$ at $300 \mathrm{~K}$ and a large excitonic Bohr radius of $18 \mathrm{~nm}$ [8]. Lead sulfide absorption band can be distorted to anywhere between near IR to UV $(0.4 \mu \mathrm{m})$ covering the entire visible spectrum, while achieving the quantum confinement region [9]. Lead sulfide nanomaterials can be utilized in numerous fields, such as invention of solar cells [10], gas sensors [11], optical switches [12], tunable near-infrared detectors [13], tunable IR lasers [14], etc. It can be synthesized to produce structures such as nanorods [15], cubes [16], star-like particles [17], nano- wires [18], hierarchical structures [19]. Lead sulfide nanoparticles have been generally synthesized by various techniques include hydrothermal [20], microwave and sonochemical methods [21], etc.

Chongad et al. [22] reported the synthesis of $\mathrm{PbS}$ nanoparticles using chemical precipitation method with the assistance of $\mathrm{H}_{2} \mathrm{~S}$ gas. Hedayati and Nabiyouni [23] reported the synthesis of $\mathrm{PbS}$ nanoparticles using 2-mercaptoethanol as the capping molecules. Their study showed that when the capping agent was not used, bulk $\mathrm{PbS}$ was obtained but when the mercapto-ethanol was added, the particles with small sizes were produced. The use of single source precursors containing both metal and chalcogenide source has been extensively investigated as an applicable approach for synthesizing semiconductor nanoparticles [24]. This method avoids problems associated with the use of toxic and volatile compounds at high temperatures. It is also known to produce nanomaterials of high quality compared to other methods.

In this work, a modified single step preparation of substituted benzimidazole dithiocarbamate- $\mathrm{Pb}$ (II) complex as single source precursor for the synthesis of lead sulfide nanoparticles is reported. The effect of capping agents such as hexadecylamine (HDA) and trioctylphosphine oxide (TOPO) as well as the effect of reaction temperature were investigated. The FTIR, elemental analysis and TGA were used to characterize the metal complex whereas UV-visible, photoluminescence, powder-XRD and TEM were employed to characterize the nanoparticles. 


\section{EXPERIMENTAL}

Lead acetate trihydrate $(99.5 \%)$, trioctylphosphine oxide (97\%), hexadecylamine (90\%), 2-methyl benzimidazole (98 $\%)$, carbon disulphide (99\%), sodium hydroxide pellets, trioctylphosphine oxide $(90 \%)$, toluene $(99.8 \%)$ and methanol $(99.5 \%)$ were purchased from Sigma-Aldrich and used without any purification.

Infrared spectra were recorded on FTIR Perkin Elmer 400 spectrometer. Spectra were collected over the range from 450 to $4000 \mathrm{~cm}^{-1}$. The elemental analysis was carried out with LecoCHNS 932 analyzer. About $2 \mathrm{mg}$ of sample was transferred into silver capsule and was placed in a furnace, which was maintained at $700{ }^{\circ} \mathrm{C}$. Thermogravimetric analysis was performed on a Perkin Elmer Pyris 6 manager TGA under an inert atmosphere of dry nitrogen and at a heating rate of $20^{\circ} \mathrm{C} / \mathrm{min}$. UVvisible and photoluminescence spectroscopy were used to determine the optical properties of $\mathrm{PbS}$ nanoparticles. The samples were placed in glass cuvettes $(1 \mathrm{~cm})$ using toluene as a solvent. Absorption spectra of the particles were measured using a Perkin Elmer Lambda 20 UV-vis Spectrophotometer. Emission spectra of the particles were recorded on a Perkin Elmer LS 45 PL spectrometer with a xenon lamp at room temperature. TEM analysis was done on a LEO JEM 912 electron microscope with an acceleration voltage of $120 \mathrm{KW}$ and a tungsten wire filament. $\mathrm{X}$-ray diffraction patterns on powdered samples were carried out in $2 \theta$ on a D8 diffractometer. Samples were placed in silicon zero background sample holder. Measurements were taken using a glancing angle of incidence detector using $\mathrm{CuK} \alpha 1$ source, for $2 \theta$ values over $20^{\circ}-90^{\circ}$ in steps of $0.05^{\circ}$.

Synthesis of dithiocarbamate- $\mathbf{P b}$ (II) complex: The complex was prepared according to the reported method by Siddiqi et al. [25]. In a typical experiment, a solution of $40 \mathrm{~mL} \mathrm{NaOH}(0.78 \mathrm{~g}$, $0.02 \mathrm{~mol}$ ) was added to 2-methylbenzimidazole ( $2.64 \mathrm{~g}, 0.02$ mol). The mixture was stirred and cooled in an ice bath for an hour. Carbon disulfide ( $1.52 \mathrm{~mL}, 0.02 \mathrm{~mol}$ ) was then added to the cold mixture dropwise and stirred for $12 \mathrm{~h}$ at room temperature. Lead acetate $(3.79 \mathrm{~g}, 0.01 \mathrm{~mol})$ which was previously dissolved in $40 \mathrm{~mL}$ of distilled water was added dropwise to dithiocarbamate solution. The mixture was refluxed for $4 \mathrm{~h}$ at $60^{\circ} \mathrm{C}$ in a waterbath. Then later, it was kept for three days in the fume hood to crystallize. The precipitate formed was filtered, washed with distilled water then followed by excess methanol and dried in an open air. 2-Methylbenzimidazole dithiocarbamate- $\mathrm{Pb}(\mathrm{II})$ complex was obtained as black solid. Yield: $45.36 \%$, m.p. = $180{ }^{\circ} \mathrm{C}$. Elemental analysis: Calc.: C, 34.77; H, 2.27; N, 9.01; S, 20.63. Found: C, 35.36; H, 2.57; N, 8.34; S, $18.91 \%$.

Synthesis of PbS nanoparticles: Lead sulfide nanoparticles were synthesized with different capping agents at different temperatures. 2-Methylbenzimidazole dithiocarbamate- $\mathrm{Pb}$ (II) complex $(0.3 \mathrm{~g})$ was dissolved in $5 \mathrm{~mL}$ of trioctylphosphine oxide (TOPO). The solution was injected into $6 \mathrm{~g}$ of hot hexadecylamine (HDA) and trioctylphosphine oxide (TOPO) in a threenecked flask at different temperatures $\left(140,160\right.$ and $\left.180{ }^{\circ} \mathrm{C}\right)$. The reaction was allowed to stabilize at the desired temperature for an hour. The reaction was allowed to cool to $70^{\circ} \mathrm{C}$ and then the excess methanol was added to flocculate the particles. The black coloured $\mathrm{PbS}$ nanoparticles formed were separated by centrifugation and washed three times with methanol.

\section{RESULTS AND DISCUSSION}

An effective approach for the synthesis of $\mathrm{PbS}$ nanoparticles capped with hexadecylamine (HDA) and trioctylphosphine oxide (TOPO) through the decomposition of 2-methylbenzimidazole dithiocarbamate- $\mathrm{Pb}(\mathrm{II})$ complex using single source molecular precursor route is reported. The effect of decomposition temperature of complex was also investigated. The dithiocarbamate metal complex was obtained from a single step process by the reaction of 2-methylbenzimidazole with carbon disulfide in the presence of $\mathrm{NaOH}$ followed by the addition of lead acetate. (Scheme-I).

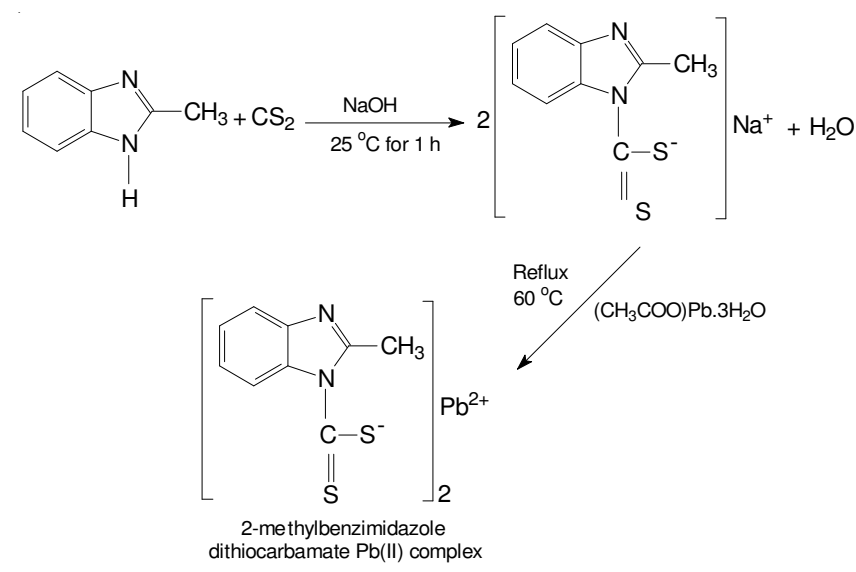

Scheme-I: Preparation of 2-methylbenzimidazole dithiocarbamate $\mathrm{Pb}$ (II) complex

The reaction conditions for the preparation of HDA or TOPO capped $\mathrm{PbS}$ nanoparticles by varying reaction temperatures using 2-methylbenzimidazole dithiocarbamate- $\mathrm{Pb}(\mathrm{II})$ complex, while keeping all the other parameters the same (Table-1).

\begin{tabular}{cccc}
\multicolumn{5}{c}{ TABLE-1 } \\
VARIATION OF TEMPERATURE IN SYNTHESIS OF PbS \\
NANOPARTICLES CAPPED WITH TOPO OR HDA \\
\hline $\begin{array}{c}\text { Surfactant }(\mathrm{HDA} / \\
\text { TOPO) mass }(\mathrm{g})\end{array}$ & $\begin{array}{c}\text { Complex } \\
\text { mass }(\mathrm{g})\end{array}$ & $\begin{array}{c}\text { Temperature } \\
\left({ }^{\circ} \mathrm{C}\right)\end{array}$ & $\begin{array}{c}\text { Time } \\
(\mathrm{min})\end{array}$ \\
\hline 6.0 & 0.3 & 140 & 60 \\
6.0 & 0.3 & 160 & 60 \\
6.0 & 0.3 & 180 & 60 \\
\hline
\end{tabular}

FTIR: The FTIR was used to determine the functional groups and formation of new bonds in the prepared complex. Fig. 1 shows FTIR spectra of 2-methylbenzimidazole and its lead complex. Normally, the dithiocarbamates ligands are capable of forming bonds with the metal through sulphur atom at the region of $1550-800 \mathrm{~cm}^{-1}$ region. The FTIR spectrum of the complex exhibited bands at 1200-1080, 1080-1040, 1474-1412 and $3382-3260 \mathrm{~cm}^{-1}$, which were due to the contribution of $v(\mathrm{C}-\mathrm{N}), v(\mathrm{C}=\mathrm{S})$ weak bands, $v(\mathrm{C}=\mathrm{N})$ strong bands and $v(\mathrm{OH})$ vibration, respectively. The absence of $v(\mathrm{~N}-\mathrm{H})$ absorption bands at 3116 and $1624 \mathrm{~cm}^{-1}$ and the presence of $v(C-N), v(C=S)$ in the spectrum of the complex confirmed the presence of lead metal in the complex. The appearence of $v(\mathrm{OH})$ absorption bands in the spectrum of the complex indicates the presence of water molecules in the complex. The absorption band in Fig. 1b at $522 \mathrm{~cm}^{-1}$ was assigned to the coordination of metal with sulfur from 2-methylbenzimidazole. 


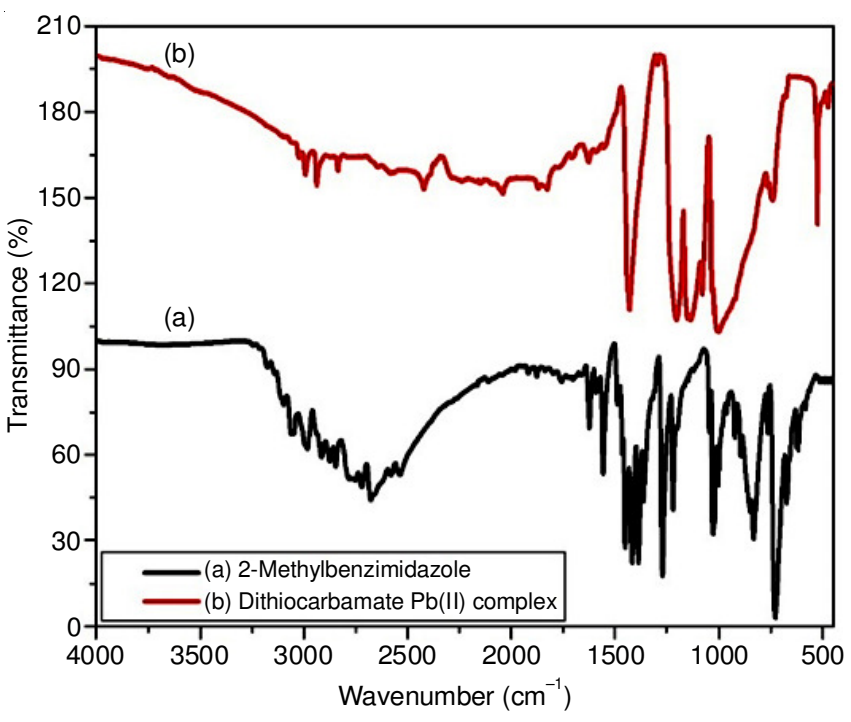

Fig. 1. IR spectra for 2-methylbenzimidazole (a) and 2-methylbenzimidazole dithiocarbamate- $\mathrm{Pb}$ (II) complex (b)

Thermogravimetric analysis: Thermal decomposition of the complexes often leads to the confirmation of significant bonding between metal centre and sulfide from the dithiocarbamate ligand formation. Fig. 2 shows TGA/DTA thermograms of 2-methylbenzimidazole dithiocarbamate- $\mathrm{Pb}(\mathrm{II})$ complex, respectively. The curve displayed two decomposition steps. The first decomposition step is due to methyl groups and evaporation of benzene groups from $90-137^{\circ} \mathrm{C}$ by $17 \%$. The second decomposition step was due to imidazole molecules from 137$217^{\circ} \mathrm{C}$ by $7 \%$. The spectrum shows that $\mathrm{PbS}$ nanoparticles was stable within $235-700{ }^{\circ} \mathrm{C}$ region. The DTA curve in dotted line illustrated that most of the weight loss occurred at $129^{\circ} \mathrm{C}$.

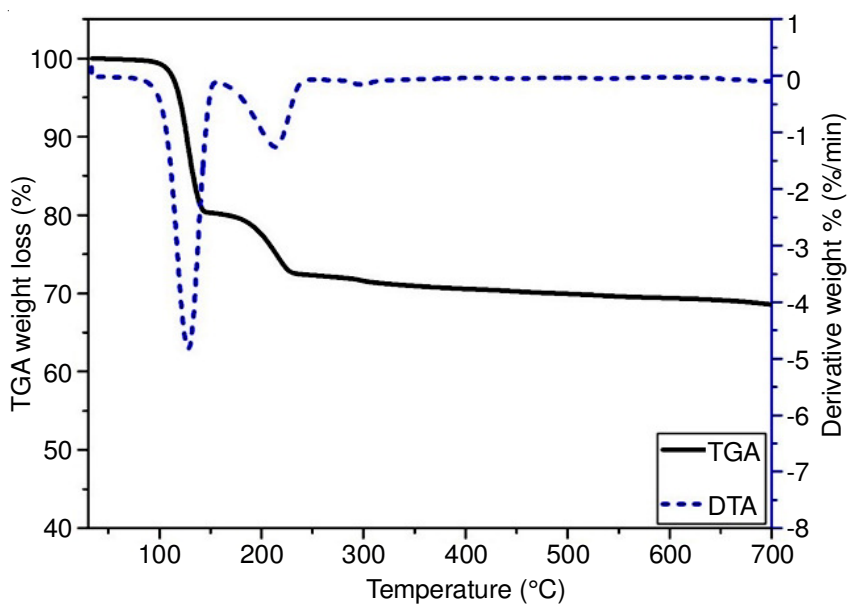

Fig. 2. TGA/DTA curves for 2-methylbenzimidazole dithiocarbamate$\mathrm{Pb}$ (II) complex

\section{PbS nanoparticles capped with hexadecylamine (HDA)}

UV-visible spectroscopy: Fig. 3 shows the absorption spectra of hexadecylamine capped $\mathrm{PbS}$ nanoparticles prepared at different temperatures and their corresponding Tauc plots. All the spectra were blue shifted relative to bulk $\mathrm{PbS}$ material, which is an indication of the formation of nanometer sized particles. The adsorption spectra also showed that as the temperature is increased, the size of the nanoparticles also increases. At low temperature, the absorption spectrum in Fig. $3 \mathrm{a}$ is sharper with the band edge at $335 \mathrm{~nm}$. This could be due to smaller sizes of $\mathrm{PbS}$ nanoparticles. When the temperature was increased to $160{ }^{\circ} \mathrm{C}$ (Fig. 3b), the band edge at $345 \mathrm{~nm}$ becomes well defined which is an indication of the well distributed particles. As the temperature was further increased to $180^{\circ} \mathrm{C}$ (Fig. 3c), a broad band edge at $346 \mathrm{~nm}$ was observed which indicates the polydispersity of particles.

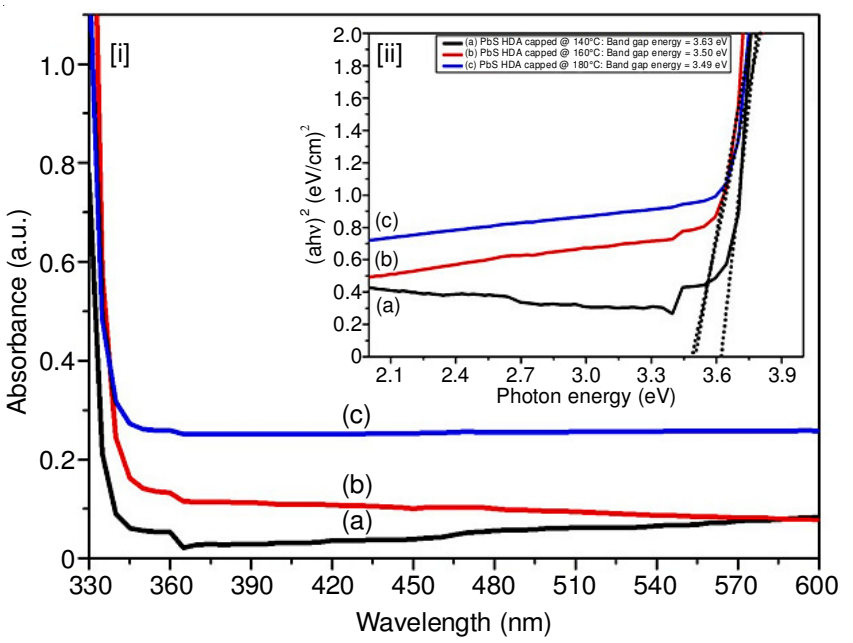

Fig. 3. Absorption spectra (a) of $\mathrm{PbS}$ nanoparticles prepared with $0.30 \mathrm{~g}$ of complex with $6.0 \mathrm{~g}$ of HDA at 140 (a), 160 (b) and $180{ }^{\circ} \mathrm{C}$ (c) and their corresponding Tauc plots (b)

As $\mathrm{PbS}$ materials display direct transition, $(\alpha \mathrm{hv})^{2}$ of photon energy hv can be plotted following Tauc relation [26] as shown in Fig. 3b. The energy gap values of $\mathrm{PbS}$ nanoparticles can be discovered by extrapolating the linear part of the plot to $(\alpha h v)^{2}$ $=0$. It has been noted that as the decomposition temperature is increased, the band gap energies decreases from 3.63 to $349 \mathrm{eV}$ which is larger than that of bulk PbS material $\left(\mathrm{E}_{\mathrm{g}}=\right.$ $0.41 \mathrm{eV}$ ) [27]. The long tail nearby the absorption edge may be attributed to the defect states or particle size distribution. These observations are in good agreement with the reported results by Karami et al. [14].

Photoluminescence: The emission spectra of $\mathrm{PbS}$ samples prepared at different temperatures are given in Fig. 4(a-c). The emission maxima of the samples were slightly red shifted from their respective band edges in the absorption spectra. The emission peaks for the sample prepared at $160^{\circ} \mathrm{C}$ have a narrow shape, which indicates good passivation of the particles. However, the nanoparticles prepared at high temperature $\left(180^{\circ} \mathrm{C}\right)$ show the broad emission peak which indicates that the particles were polydispersed or agglomerated. The emission maximum was shifting towards the lower wavelength as the temperature was decreased. The emission peaks maxima were observed at 323, 364 and $405 \mathrm{~nm}$, respectively. The difference between absorption and emission peak wavelength at low temperatures was very small. This is an indication of emission that is associated with the transition of electrons from trap state to conduction band [28].

X-Ray Diffraction: Fig. 5 shows XRD patterns of hexadecylamine capped $\mathrm{PbS}$ nanoparticles at different temperatures. All the patterns of nanoparticles prepared at different temperatures revealed (111), (200) and (311), (222), (400), (331) and 


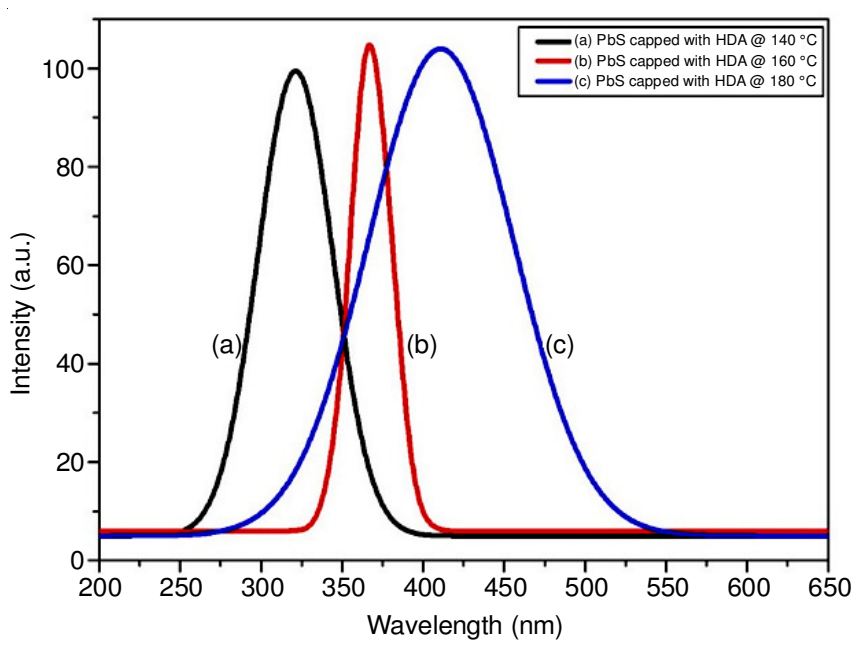

Fig. 4. Emission spectra of $\mathrm{PbS}$ nanoparticles prepared with $0.3 .0 \mathrm{~g}$ of complex and $6.0 \mathrm{~g}$ of HDA at 140 (a), 160 (b) and $180{ }^{\circ} \mathrm{C}$ (c)

(420) planes which corresponds to the cubic phase (galena) of $\mathrm{PbS}$. These results are in good agreement with the standard value (JCPDS file no.03-065-2935).

TEM: The TEM images of hexadecylamine capped PbS nanoparticles synthesized at different temperatures are shown in Fig. 6(a-c). The TEM images shows the cube like structures. It was observed that when the temperature was increased, the size of nanoparticles also increased which is be due to Ostwald ripening. The estimated average particle sizes were found to be $16.89 \pm 8.02,22.089 \pm 7.53$ and $27.91 \pm 6.949 \mathrm{~nm}$ for $\mathrm{PbS}$ nanoparticles prepared at 140,160 and $180^{\circ} \mathrm{C}$, respectively. These results were consistent with those obtained from X-ray diffraction. There is no significant change in shape when the

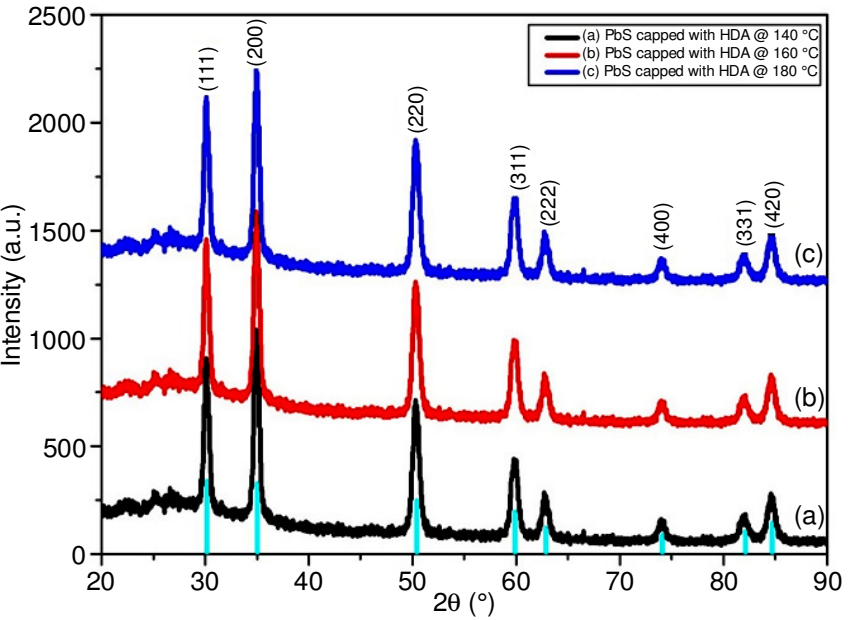

Fig. 5. XRD patterns of $\mathrm{PbS}$ nanoparticles prepared with $0.30 \mathrm{~g}$ of complex with $6.0 \mathrm{~g}$ of $\mathrm{HDA}$ at 140 (a), 160 (b) and $180^{\circ} \mathrm{C}$ (c)

temperature was varied and this is due to thermodynamic growth regime. Nevertheless, the particles were found to be polydispersed as shown by the corresponding distribution curves.

$\mathrm{PbS}$ nanoparticles capped with trioctylphosphine oxide (TOPO)

UV-visible spectroscopy: Absorption spectra of trioctylphosphine oxide (TOPO) capped PbS nanoparticles prepared at different temperatures and their Tauc plots are shown in Fig. 7. The absorption band edges in Fig. 7(a) were observed at 343,344 and $346 \mathrm{~nm}$. The absorption band edges show the blue shift in relative to bulk PbS material and this confirms the quantum size effect of $\mathrm{PbS}$. The broadening of the band edges at higher temperatures is an indication of a broader size distri-
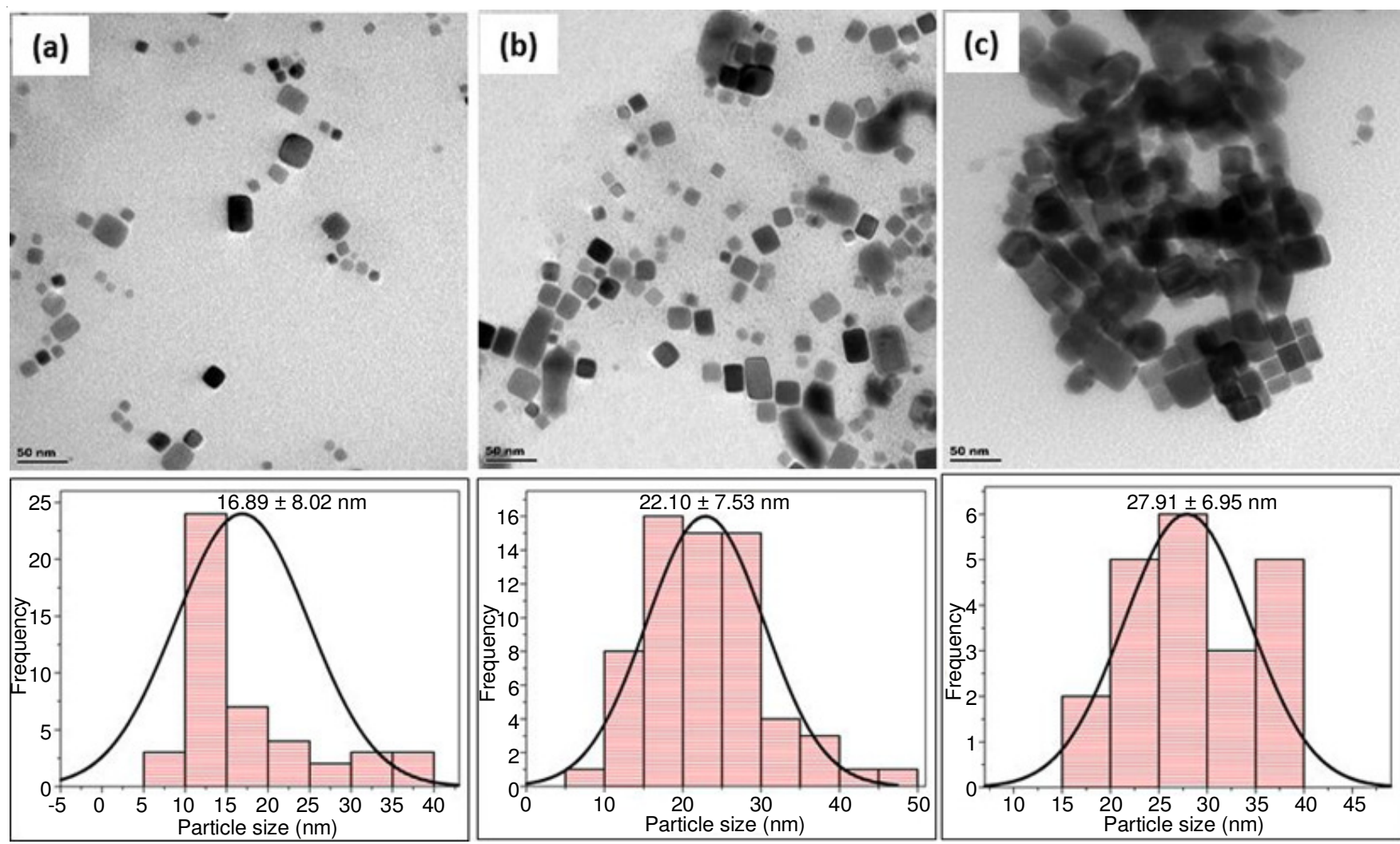

Fig. 6. TEM images of PbS nanoparticles prepared with $0.30 \mathrm{~g}$ of complex with $6.0 \mathrm{~g}$ of HDA at 140 (a), 160 (b) and $180{ }^{\circ} \mathrm{C}$ (c) 
bution or the presence of larger elongated particles. It has been noted that as the decomposition temperature is increased, the band gap energies in Fig. $7 \mathrm{~b}$ decreases from 3.55 to $343 \mathrm{eV}$ which is also larger than that of bulk $\mathrm{PbS}$ material as mentioned on the results of $\mathrm{PbS}$ nanoparticles capped with hexadecylamine.

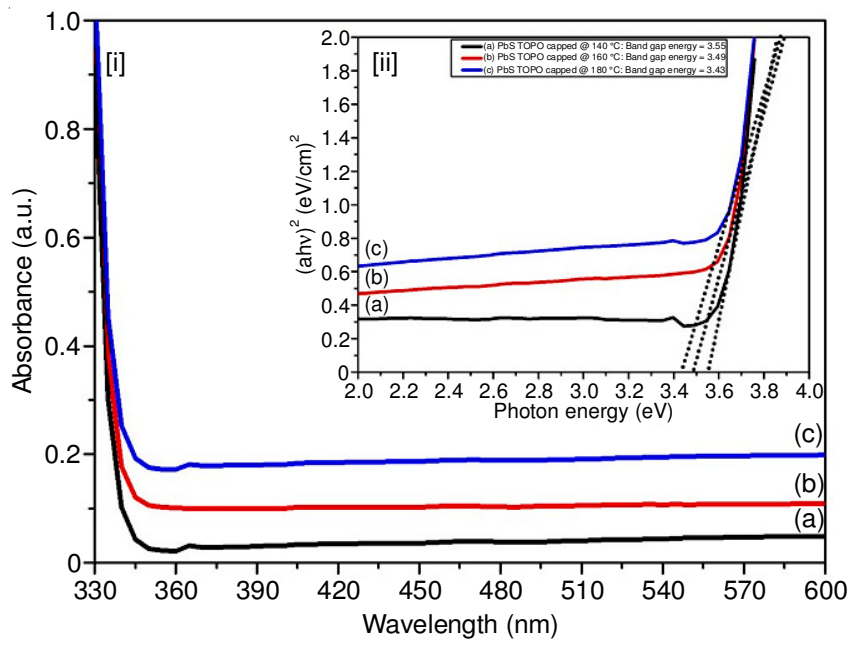

Fig. 7. Absorption spectra (a) of $\mathrm{PbS}$ nanoparticles prepared with $0.30 \mathrm{~g}$ of complex with $6.0 \mathrm{~g}$ of TOPO at 140 (a), 160 (b) and $180{ }^{\circ} \mathrm{C}$ (c) and their corresponding Tauc plots (b)

Photoluminescence: The emission spectra (Fig. 8) shows broad emission peaks with the maxima at 417, 427 and 436 $\mathrm{nm}$ from low temperature to high temperature which is an indication of large size distribution. The emission spectra were red shifted in relative to the absorption spectra.

X-Ray Diffraction: Fig. 9 shows XRD patterns of $\mathrm{PbS}$ nanoparticles capped with TOPO at different temperatures. The XRD results showed eight peaks corresponding to $\mathrm{PbS}$ compound. The presence of (111), (200), (220), (311), (222), (400), (331) and (420) planes in the diffraction patterns are the characteristic of cubic phase (galena) $\mathrm{PbS}$ which is in good agreement with the standard value (JCPDS file no.03-065-2935). The PbS nanoparticles are purer since there were no other peaks observed in the XRD spectra. Debye-Scherer equation (eqn. 1) was used to determine the particle sizes of TOPO capped $\mathrm{PbS}$ nanoparticles.

$$
\mathrm{D}=0.9(\lambda) / \beta \cos \theta
$$

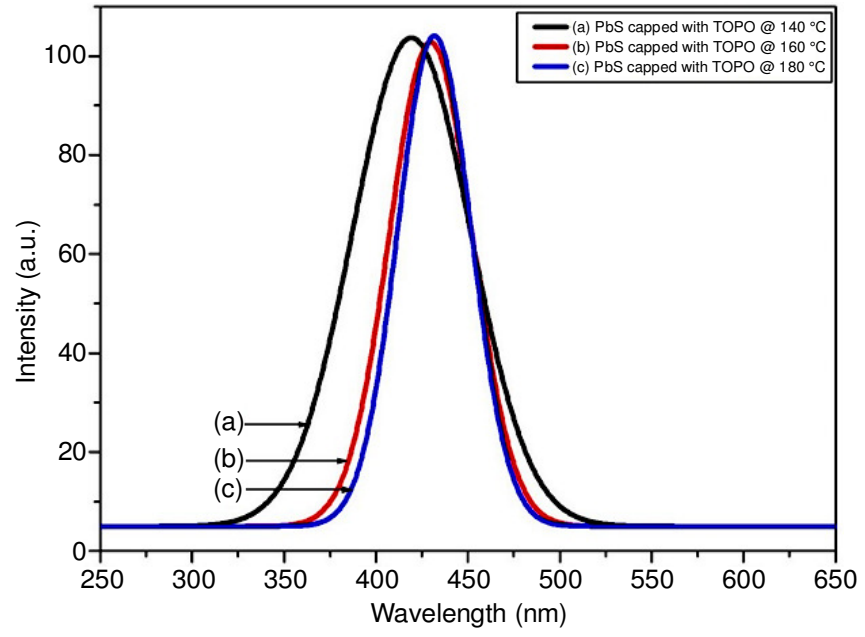

Fig. 8. Emission spectra of $\mathrm{PbS}$ nanoparticles prepared with $0.30 \mathrm{~g}$ of complex with $6.0 \mathrm{~g}$ of TOPO at $140(\mathrm{a}), 160$ (b) and $180^{\circ} \mathrm{C}$ (c)

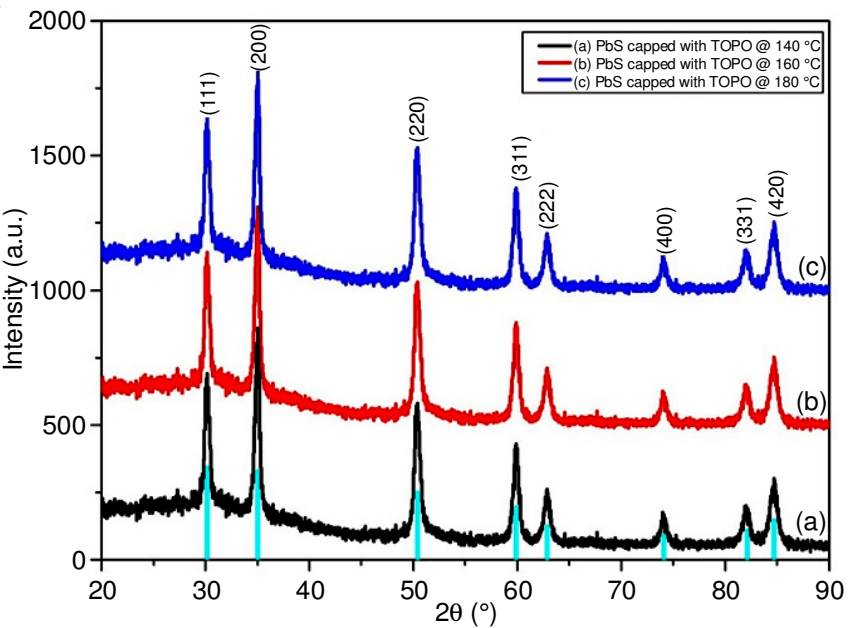

Fig. 9. XRD patterns of $\mathrm{PbS}$ nanoparticles prepared with $0.30 \mathrm{~g}$ of complex with $6.0 \mathrm{~g}$ of TOPO at 140 (a), 160 (b) and $180{ }^{\circ} \mathrm{C}$ (c)

where, $\mathrm{D}(\mathrm{nm})$ is the average particle size, $\lambda(\mathrm{nm})$ is the wavelength, $\theta$ (degrees) is the diffraction angle, and $\beta$ is the maximum peak width in half-height. The average size of particles at 140,160 and $180^{\circ} \mathrm{C}$ were found to be $19.88,15.38$ and 16.50 $\mathrm{nm}$, respectively.
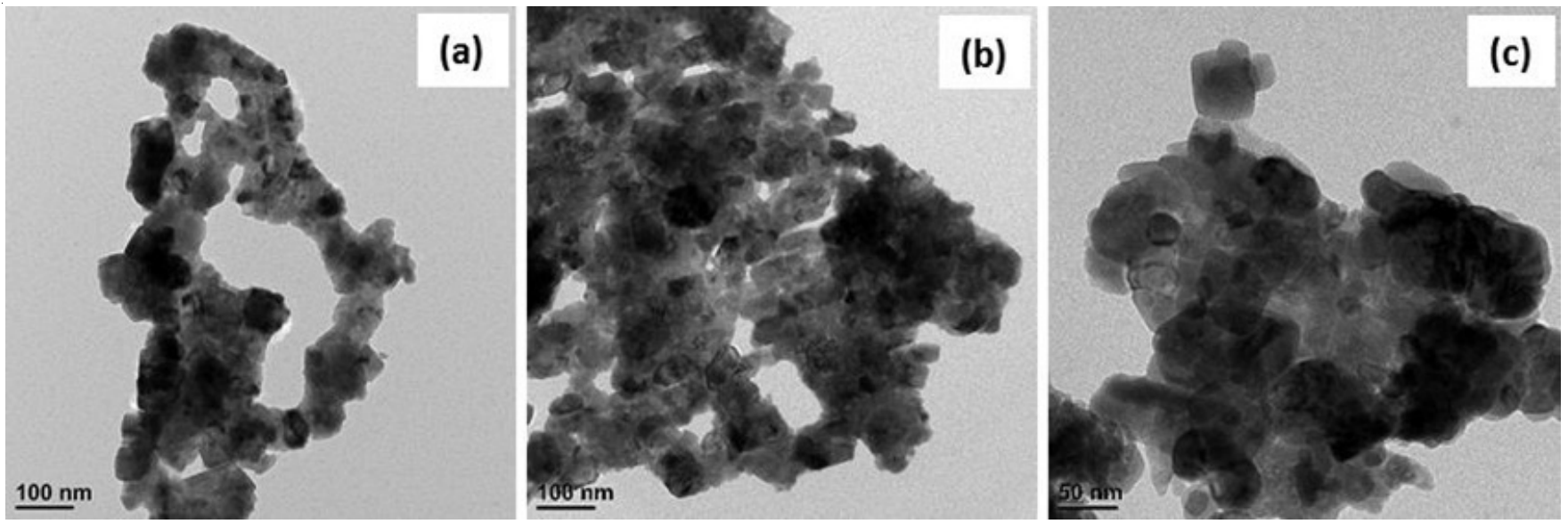

Fig. 10. TEM images of PbS nanoparticles prepared with $0.30 \mathrm{~g}$ of complex with $6.0 \mathrm{~g}$ of TOPO at (a) 140 (a), 160 (b) and $180{ }^{\circ} \mathrm{C}$ (c) 
TEM: Fig. 10 shows TEM images of TOPO capped PbS nanoparticles synthesized at different temperatures. All the $\mathrm{PbS}$ nanoparticlesTEM images show agglomerated particles as the temperature was varied, which can be attributed to the large steric hindrance of TOPO creating a small capping density for the particles. The observed morphology was found to be cubes at low temperature but as the temperature was increased, cylindrical shaped particles were observed.

\section{Conclusion}

Lead sulfide $(\mathrm{PbS})$ nanoparticles were synthesized from 2 -methylbenzimidazole dithiocarbamate- $\mathrm{Pb}$ complex. The spectroscopic results and elemental analysis confirmed that dithiocarbamate complex was a dimer substance which exhibits the doublet $\mathrm{C}=\mathrm{S}$ band. The optical measurements showed that decomposition temperature plays a significant role during the synthesis of nanomaterial. The results also showed that when the temperatures is increased during the synthetic process, the sizes of $\mathrm{PbS}$ nanoparticles also increases. The effect of capping molecule was also investigated. The results hexadecylamine (HDA) based nanoparticles gave well resolved $\mathrm{PbS}$ nanoparticles than trioctylphosphine oxide (TOPO) capped nanoparticles at all temperatures. The powder XRD patterns for $\mathrm{PbS}$ nanoparticles capped with hexadecylamine or trioctylphosphine oxide exhibited cubic morphologies at all temperatures. The TEM images of HDA capped $\mathrm{PbS}$ showed cubic structured particles compared to TOPO capped $\mathrm{PbS}$ nanoparticles, which displayed anisotropic shapes particles were agglomerated.

\section{ACKNOWLEDGEMENTS}

The authors would like to acknowledge the Vaal University of Technology and National Research Foundation (NRF Thuthuka) for the funding this project.

\section{REFERENCES}

1. C. Xu, Z. Zhang and Q. Ye, Mater. Lett., 58, 1671 (2004); https://doi.org/10.1016/j.matlet.2003.11.005.

2. Z.Zhang, W.P. Lim, C.T. Wong, H. Xu, F. Yin and W.S. Chin, Nanomaterials, 2, 113 (2012); https://doi.org/10.3390/nano2020113.

3. S. Suresh, Nanosci. Nanotechnol., 3, 63 (2013); https://doi.org/10.5923/j.nn.20130303.06.

4. M.C. Roco, J. Nanopart. Res., 1, 1 (1999); https://doi.org/10.1023/A:1010093308079.

5. Z. Niu and Y. Li, Chem. Mater, 26, 72 (2014); https://doi.org/10.1021/cm4022479.

6. H. Tang, M. Yan, H. Zhang, M. Xia and D. Yang, J. Mater. Lett., 59, 1024 (2005); https://doi.org/10.1016/j.matlet.2004.11.049.

7. A.C. Deshpande, S.B. Singh, M.K. Abyaneh, R. Pasricha and S.K. Kulkarni, Mater. Lett., 62, 3803 (2008);

https://doi.org/10.1016/j.matlet.2008.04.082.
8. M. Salavati-Niasari, D. Ghanbari and M.R. Loghman-Estarki, Polyhedron, 35, 149 (2012); https://doi.org/10.1016/j.poly.2012.01.010.

9. Y. Wang, A. Suna, W. Mahler and R. Kasowski, J. Chem. Phys., 87, 7315 (1987); https://doi.org/10.1063/1.453325.

10. A.A.R. Watt, D. Blake, J.H. Warner, E.H. Thomsen, E.L. Tavenner, H. Rubinsztein-Dunlop and P. Meredith, J. Phys. D Appl. Phys., 38, 2006 (2005); https://doi.org/10.1088/0022-3727/38/12/023.

11. E. Comini, Anal. Chim. Acta, 568, 28 (2006); https://doi.org/10.1016/j.aca.2005.10.069.

12. F.W. Wise, Acc. Chem. Res., 33, 773 (2000); https://doi.org/10.1021/ar970220q.

13. S.A. McDonald, G. Konstantatos, S. Zhang, P.W. Cyr, E.J.D. Klem, L. Levina and E.H. Sargent, Nat. Mater., 4, 138 (2005); https://doi.org/10.1038/nmat1299.

14. H. Karami, M. Ghasemi and S. Matini, Int. J. Electrochem. Sci., 8, 11661 (2013).

15. R. Yousefi, M. Cheraghizade, F. Jamali-Sheini, W.J. Basirun and N.M. Huang, Curr. Appl. Phys., 14, 1031 (2014); https://doi.org/10.1016/j.cap.2014.05.010.

16. S.S. Sun, Q.F. Han, X.D. Wu, J.W. Zhu and X. Wang, Mater. Lett., 65, 3344 (2011); https://doi.org/10.1016/j.matlet.2011.07.030.

17. M. Salavati-Niasari and D. Ghanbari, Particuology, 10, 628 (2012); https://doi.org/10.1016/j.partic.2012.02.003.

18. Z. Wang, B. Zhao, F. Zhang, W. Mao, G. Qian and X. Fan, Mater. Lett., 61, 3733 (2007); https://doi.org/10.1016/i.matlet.2006.12.085.

19. A. Mocanu, E. Rusen, A. Diacon and A. Dinescu, Powder Technol., 253, 237 (2014); https://doi.org/10.1016/j.powtec.2013.11.018.

20. S. Wang, A. Pan, H. Yin, Y. He, Y. Lei, Z. Xu and B. Zou, Mater. Lett., 60, 1242 (2006); https://doi.org/10.1016/j.matlet.2005.10.116.

21. Y. Zhao, X.-H. Liao, J.-M. Hong and J.-J. Zhu, Mater. Chem. Phys., 87, 149 (2004); https://doi.org/10.1016/j.matchemphys.2004.05.026

22. L.S. Chongad, A. Sharma, M. Banerjee and A. Jain, J. Phys. Conf. Ser, 755, 012032 (2016); https://doi.org/10.1088/1742-6596/755/1/012032.

23. K. Hedayati and G. Nabiyouni, Appl. Phys., A Mater. Sci. Process., 116, 1605 (2014); https://doi.org/10.1007/s00339-014-8288-4

24. T. Mthethwa, V.S.R.R. Pullabhotla, P.S. Mdluli, J. Wesley-Smith and N. Revaprasadu, Polyhedron, 28, 2977 (2009); https://doi.org/10.1016/j.poly.2009.07.019.

25. K.S. Siddiqi, S.A.A. Nami, Lutfullah and Y. Chebude, J. Braz. Chem. Soc., 17, 107 (2006); https://doi.org/10.1590/S0103-50532006000100016.

26. J. Tauc, R. Grigorovici and A. Vancu, Phys. Status Solidi, 15, 627 (1966); https://doi.org/10.1002/pssb.19660150224.

27. R. Thielsch, T. Böhme, R. Reiche, D. Schläfer, H.-D. Bauer and H. Böttcher, Nanostruct. Mater, 10, 131 (1998); https://doi.org/10.1016/S0965-9773(98)00056-7.

28. M. Navaneethan, K.D. Nisha, S. Ponnusamy and C. Muthamizhchelvan, Rev. Adv. Mater. Sci., 21, 217 (2009). 